\title{
Culture-bound syndromes and the neglect of cultural factors in psychopathologies among Africans
}

\author{
OF Aina1, 0 Morakinyo² \\ ${ }^{1}$ Department of Psychiatry, College of Medicine of the University of Lagos, Lagos, Nigeria \\ 2Department of Mental Health, College of Medical Sciences, University of Benin, Benin City, Nigeria
}

\begin{abstract}
One of the major problems in psychiatric practice worldwide is inability to reach a consensus as regards a globally acceptable classificatory system for the different psychopathologies. Consequently, apart from the WHO's International Classification of Diseases (ICD) that is expected to be universally applicable there are regional-based classificatory systems in some parts of the world. In Africa, a number of culture bound syndromes (CBS) have been described which have not been given international recognition. The possible consequences of this non-recognition are highlighted in this paper. Unfortunately there are serious constraints such as the relatively small number of psychiatrists on the continent, and inadequate funding for mental health research, which militate against producing an African classificatory system. Nevertheless, it is proposed that reports of African psychiatrists emanating from their research and clinical experience should be accorded adequate recognition in the WHO so as to assign these CBS their rightful placement in the International classificatory system.
\end{abstract}

Key Words: Culture-Bound Syndromes; African Psychiatry; Classification; Recognition.

Received: 11-09-2010

Accepted: 14-12-2010

doi: http://dx.doi.org/10.4314/ajpsy.v14i4.4

\section{Introduction}

Culture has been variously described. From the sociological aspect, Hobbs and Blank defined it as "that complex whole that includes knowledge, beliefs, art, morals, laws, customs and any other habits and capabilities acquired by human beings as members of society".' Thus, culture refers to all those ways of thinking, feeling and behaviour that are socially and not biologically transmitted from one generation to the next. ${ }^{1}$ In relation to psychiatric practice, the National Institute of Mental Health's Culture and Diagnosis Group defined culture as "meanings, values and behavioural norms that are learned and transmitted in the dominant society and within its social groups. Culture powerfully influences cognition, feelings and self-concept as well as the diagnostic process and treatment decisions". ${ }^{2}$ Culture is thus best conceptualised as a totality composed of a complex system of symbols possessing subjective dimensions such as values, feelings and ideals and objective dimensions including beliefs, traditions and behavioural prescriptions articulated into laws and practice. ${ }^{2}$

Psychiatry is deeply rooted in the social, cultural and political life of the times. Currently, two main schools of thought exist about the interrelationship between culture and psychiatry. One, the universalistic school argues that the basic psychopathology of all mental disorders is universal, and that cross-cultural differences in clinical patterns derive mainly from culture-specific illness behaviour. The stance of this school is that culture is only pathoplastic. Thus, a large body of descriptive literature exists demonstrating how cultural processes affect psychiatric illness in addition to neurobiological and genetic risk factors. A classic example of this was a paper on cultural factors and paranoid psychosis among the Yoruba by Lambo in 1955'; and another example is the work by Binitie on the somatic manifestations of 
depression in Africans. ${ }^{4}$ A more recent example is the report by Morakinyo demonstrating how phobia may present with somatic complaints syndromes in Africans in contrast to what obtains in the West. ${ }^{5}$

The universalistic school, though etic and occidental in its approach stemmed from the biomedical model of man which in turn leans on the philosophy of reductionism. Another consequence of this approach is the fallacious assumption that instruments which have been designed and validated for detecting and measuring psychopathologies in the West should be applicable globally.

The second school of thought adopts an emic approach, and has been described as the relativistic school. It advocates that a full aetiological understanding of many psychopathologies depend largely on appropriate cultural factors. In addition, there are a number of disorders which have been found to be culture-specific and in which cultural factors have been demonstrated to play major aetiological role. In other words, cultural factors can be pathogenic as well as pathoplastic. This group of disorders have been tagged "Culture-Bound Syndromes (CBS)". Perhaps, the most persuausive argument in this respect emanate from Prince using Brain Fag Syndrome as an example. ${ }^{6,7}$

In the current paper, we draw attention to the neglect of this group of disorders and the apparent reluctance to recognize them as distinct psychopathological entities in the international classificatory systems such as the WHO International Classification of Diseases and Causes of Death (WHO-ICD). ${ }^{8}$

A full aetiological understanding of many psychiatric disorders will require consideration of psychological and cultural factors.

\section{Culture - Bound Syndromes (CBS)}

CBS, previously known as "Cultural and ethnic psychoses and neuroses" or "atypical and exotic psychotic syndrome" are described as "Culturally based signs and symptoms of mental distress or maladaptive behaviour that are prominent in folk belief and practice". ${ }^{2}$ Such patterns are informed by native cultural assumptions, sorcery, break of taboo, intrusion of a disease object, intrusion of a disease-causing spirit, or loss of soul. ${ }^{2}$ CBS are caused and maintained by culture specific psychological factors such as beliefs, values and attitudes. A number of CBS, such as "Koro", "Amok", "Latah" etc have been described in the international classificatory system., ${ }^{8,9}$

\section{CBS in West Africa and problems of clinical classification}

Apart from the well-known strong cultural influence on symptomatic expression of most psychopathologies among Africans ${ }^{4-6,10-12}$ quite a number of CBS have been described among West Africans most of which are yet to be incorporated in the internationally accepted classificatory systems. ${ }^{13-16}$ This non-recognition could partly be due to the observed dominance of western psychiatric concepts. There has been 'rebellion' against this domination even within the western world. A notable case is North America through the American Psychiatric
Association (APA) that produced the Diagnostic and Statistical Manual (DSM) for use rather than adopting the International Classification of Diseases (ICD) by WHO. Others include the Scandinavian countries whose proposed psychogenic psychosis was excluded from the WHO's ICD.

In Africa, there are many CBS in the continent that are not given due recognition in the international classificatory systems. However, a number of constraints militate against producing an African-based diagnostic system, including: the heterogeneity and large geographical spread of Africa, too few psychiatrists practicing in the continent and the problem of poor health funding. The observed media reports of such cases (for example, "magical penis loss") 17 , and increased number of cases presenting in health facilities with attendant treatment challenges ${ }^{11,18}$, definitely warrants greater clinical attention and scientific study. Consequently, the aims of this paper is to illustrate the importance of these CBS, some of which are described, bearing in mind others that exist in various regions of Africa that have not been described; and to advocate a greater presence of African psychiatry in WHO so as give due recognition to these syndromes in future revision of ICD.

\section{Methods}

The West African sub-region occupies about 20\% of Africa. It is made up of sixteen countries including five Anglophone, nine Franco-phone and three Luso-phone nations. The 2006 total population estimate was put at 251,646,263.19 Generally, there are a variety of cultures in West Africa but with prominent similarities in customs and beliefs, dress, food, music, religion etc, hence one may talk of a West African culture that is different from other parts of the world. ${ }^{20}$

A comprehensive literature search was conducted related to culture bound syndromes in West Africa. A systematic search using African Journals Online (AJOL), Medline, International Network for the Availability of Scientific Publication (INASP), Google and Yahoo search lines did not yield much relevant literature on the subject. Search terms used included: "Culture", "Medicine", "Psychiatry", "Mental Health", "Mental Illness", Culture Bound Syndromes", "Africa", "West Africa". Furthermore, then specific name of each country in the sub-region was paired to each of these search terms. To overcome the poor yield from the systematic search, the authors carried out a manual search in medical/university libraries of the following institutions in south west, Nigeria:

- University of Lagos, Idi-Araba and Akoka campuses

- University of Ibadan

- Obafemi Awolowo University, Ile-Ife

- Federal Neuropsychiatry Hospital, Yaba, Lagos.

- Federal Neuropsychiatry Hospital, Aro-Abeokuta

Further material was obtained from personal contact and communications with some psychiatrists and other relevant professionals in the sub-region through attendance at conferences and other scientific programmes- especially those organized by two important postgraduate medical colleges in the sub-region: The West African Postgraduate Medical College and National Postgraduate Medical College of Nigeria. 


\section{Results}

Four disorders which would qualify as CBS were found to have been described in West Africa. These are

- The Brain Fag Syndrome

- Koro and Koro-like (Magical penis loss) syndrome

- Ode Ori

- Ogun Oru

In addition, are the so called culture bound concepts such as "Abiku" or "ogbanje" and "Pobough Lang".

\section{Brain Fag Syndrome (BFS)}

BFS was first described by Raymond Prince among students in the western part of Nigeria in 1960,6,1,21,22 It is very common among African students and others whose work requires intensive reading or other intellectual activities. The syndrome has also been described in other countries of West Africa ${ }^{23,24}$ and even beyond the west African sub-region in Uganda ${ }^{25}$ and other East African countrie ${ }^{26}$ and South Africa. ${ }^{27}$

The main clinical features of BFS include unpleasant head and neck symptoms such as pain, burning and crawling sensations; visual disturbances of dimmed vision, pain and tearfulness in the eyes; cognitive impairments such as inability to concentrate, poor retention and inability to grasp the meaning of written or spoken words. Other symptoms are body weakness, burning or migrating pains. ${ }^{28}$ All these symptoms occur or are exacerbated while reading or occasionally while listening to lectures. Most often the symptoms commence during periods of intensive reading prior to examinations, and the students would often state that their brains are "fatigued" Thus, the students themselves attributed their symptoms to overwork of their brains. ${ }^{28}$

In terms of nosological description, many authors have suggested BFS is a depressive equivalent or "masked" depression. ${ }^{29}$ Evidence for this is its successful treatment with antidepressant drugs in some reports. Few authors have claimed however that the syndrome is a form of anxiety disorder while other authors would consider it as a mixture of anxiety and depression. However, the argument about the taxonomy of this disorder is finally being laid to rest following the publication by Prince regarding its distinct nosological entity. An instrument, the Brain Fag Syndrome Scale (BFSS) is now in existence for the detection and measurement of the intensity of the syndrome.

Epidemiologically, BFS has been reported as much commoner in males than in females ${ }^{22}$; with prevalence rates of the syndrome varying from $25 \%$ to $58 \%{ }^{28}$

In terms of aetiology, Morakinyo did extensive work in this regard. 31,32,33 Among his findings were that subjects with BFS tend to score high on the neuroticism scale of the Eysenck Personality Inventory (EPI), have a high achievement orientation, come from economically deprived social background and sleep deprivation during intensive study for examination most often with use of amphetamines or strong coffee to keep them awake. Morakinyo summarized his findings thus; "BFS represents a vicious circle in which the impairment of cognitive functions threatens the patient's ambitions, causing a state of anxiety which in turn requires the patient to spend more time in study, even at the expense of sleep. It now seems that anxiety and sleep deprivation may act by reducing verbal learning ability". 33

The management of BFS includes the use of anxiolytics but preferably antidepressant drugs combined with psychotherapy such as supportive therapy, cognitive therapy and relaxation techniques.

Finally, a very important trend in the study of BFS is the use of psychometric instruments to detect the presence of and/or to determine the severity of the syndrome ${ }^{34,35}$; of particular note is the recent work of Fatoye and Morakinyo. ${ }^{36}$

\section{"Koro" and "Koro-like" ("Magical penis loss") syndromes in West Africa}

Koro also known as 'Suo-yang' in Mandarin or 'shook-yang' in Cantonese, means "shrinking penis". ${ }^{37}$ The concept of suo-yang has been known since 7000 BC in Northern China, but was not well articulated until between 476 and 221 BC in the first Chinese textbook of Medicine, Nei Ching. ${ }^{37}$

According to DSM-IV, "Koro" is defined as "an episode of sudden and intense anxiety that the penis (or in females, the vulva and nipples) will recede into the body and possibly cause death". 38 "Koro" consists of a triad of perceptual, cognitive and emotional features: firstly, there is the perception that a protruding organ, usually the penis, but possibly the female breasts or the tongue is retracting into the body. Secondly, is the belief that a complete retraction of the organ will lead to death. The third component of the triad is that the experience is accompanied by emotions of fear, anxiety and panic. ${ }^{39}$ There are two forms of "Koro" viz: epidemic and isolated types. The epidemic type is predominantly found in south east Asia. This affects many people at once over a geographical area often as a consequence of rumour with an acute clinical presentation and resolution and is reported to have underlying cultural basis. ${ }^{39-43}$ From a psychoanalytic perspective, "koro" is said to represent a variant of Freud's castration complex ${ }^{39}$, which Kobler earlier described as an acute castration fear based on superstition. ${ }^{44}$ A popular idea by Block is the suggestion that "Koro" originated from the Malay word for tortoise: "Kuro", since the tortoise can retract its head into its shell. ${ }^{37}$ A sociological explanation has been offered to this epidemic type of "Koro". It is neither a mental illness nor an objectively real occurrence but, rather, a form of collective behaviour, hence the suggested concept of a "mass sociogenic illness"; whose outbreaks tend to disproportionately affect a subgroup of the population. ${ }^{39}$ On the other hand, isolated "Koro" occurs in diverse places all over the world, in varieties of people with little or no cultural basis for the disorder; and is often associated with medical or psychiatric abnormalities which usually persist despite treatment. ${ }^{45}$ Thus, isolated koro has been described in association with a general medical condition in a French Canadian $^{46}$, in a British man after a heroin withdrawal ${ }^{47}$, and cases secondary to epilepsy, stroke and HIV. ${ }^{48,49}$

In West Africa, a few documented cases of Koro - mostly from Nigeria- have been reported ${ }^{50-52}$ and these were in association with mental illness. However, the more important and celebrated cases (especially in the media) in West Africa are those of "Koro-like" or what Ilechukwu termed "Magical Penis Loss". ${ }^{53}$ In documented cases of the Nigerian epidemics of "Magical Penis Loss" syndrome, 
Ilechukwu, earlier described the following scenario: "the penis (and sometimes the breasts) were more often said to vanish rather than shrink (as in the case in "Koro" syndrome); when they 'vanished' they did not lodge inside the body but were supposed to have been magically 'taken' by spiritually powerful persons or their agents for ritual purposes". ${ }^{54}$

Again, a four stage sequence in the Nigerian pattern of genital loss could be identified: cue, flash, check and alarm. ${ }^{54}$ The cue was usually of a stranger asking for the time of the day or for help in following directions often written down on a piece of paper. It could also take the form of ordinary body contact such as handshake or an accidental bump of body or shoulder on the street, which was thought to be deliberately contrived. Following a cue, most victims reported a flash, like an electric shock, a sickening feeling or a chill or movement within the scrotum. The check was a very brief phase in which the afflicted person reached out for his external genitalia to check for their intactness and confirm his feeling that the genitalia had indeed been 'taken'. With the conviction that the genitals had vanished, he sounded a loud alarm. In Lagos, the commercial capital and the most populous city in Nigeria, the typical alarm was "Ole! Oko mi ti loo" ("Thief! my genitals are gone!"). The person would often strip publicly to convince sympathizers that his penis had indeed been 'taken'. A crowd would immediately get involved and the person responsible for the 'theft' was identified and either implored to return the penis or roughly threatened. Subsequently, some 'victims' realised that their genitals were 'returned' at the time they raised the alarm or that, although the penis had been 'returned', it was shrunken and so probably a 'wrong' one or just the ghost of a penis. The mob usually continued to beat or lynch the 'genital thief.'53 According to Ilechukwu, "Magical Penis Loss" epidemics had been reported during several periods in 1980 and 1990 in the Nigerian Press. ${ }^{53}$ For years, there has been some lull in the press reporting of such cases until recently when there was an observed resurgence following another report in the "Punch" newspaper of February 12008 captioned "Okada rider alleges theft of private part". ${ }^{17}$ In this report the 'okada' (commercial motorcycle) rider based in Abuja Nigeria alleged that a passenger he picked up used "spiritual" pigeon to steal his penis. ${ }^{17}$ "Magical Penis Loss" syndrome has both mental health and forensic implications. One, the "victims" could be suffering from erstwhile erectile dysfunction and/or delusional disorder prior to the public alarm. Secondly, the "genital thief" could most times wrongly suffer injustice or even die from "jungle justice" of the "concerned" mob. ${ }^{18}$

\section{Ọde ori}

"Ode ori" is a Yoruba word which literally means "hunter of the head". According to Raymond Prince, it was one of the most prominent psychopathologies in the classification of mental illnesses among the traditional healers in Yoruba-land of southwest Nigeria. ${ }^{55}$ This was corroborated by Simpson in his study of Ibadan traditional healers. ${ }^{56}$ "Ode Ori" is a condition with the core symptoms of a sensation of an organism crawling through the head and sometimes through other body parts, together with noises in the ears and various other somatic complaints including palpitations. ${ }^{55,56}$

The first extensive scientific study of "Ode Ori" was carried out by Makanjuola. ${ }^{57} \mathrm{He}$ administered the Present State Examination (PSE) ${ }^{58}$ to 30 patients that presented in the psychiatric unit of a Nigerian teaching hospital; and who were earlier diagnosed each to have "Ode Ori" by traditional healers. Among his findings, the most frequently reported symptoms included: crawling sensation, noise in ears, palpitation, peppery sensation, darkened vision ("Oju sisu"), dizziness ("Oyi"), headache, other body pains and itching or tickling sensation in that descending order of frequency. ${ }^{57}$ Using the 3rd edition of the Diagnostic and Statistical Manual (DSM) of mental disorders ${ }^{59}$, the diagnoses made on the subjects - in order of descending frequency were: major depressive episode (10), schizophrenia (4), generalized anxiety disorder (4), atypical anxiety (3), atypical psychosis, dysthymic disorder, atypical depression (2 each), schizophreniform disorder, manic episode and agoraphobia ( 1 each). ${ }^{57}$ With this diverse range of diagnoses, it was concluded that the diagnosis of "Ode Ori" by Yoruba traditional healers does not fit into any particular western diagnostic category but could be a reflection of the tendency to somatise symptoms of psychiatric illness among the Yourba and sub-Saharan Africans generally. ${ }^{57}$ The orthodox management of "Ode Ori" cases was determined by the primary psychiatric diagnoses, but generally employing pharmacotherapy and psychotherapy. However, the long-term prognosis was found to be poor as the somatic, auditory and visually related symptoms tend to persist. ${ }^{57}$

Perhaps, the clinical significance of the diagnosis of "O de Ori" is the prominent somatic component of the symptoms. Extensive research has been conducted in the past on functional somatic complaints and somatisation of mental disorders among Africans. ${ }^{10-13,15,60,61}$ Another probable explanation for the concern to have the traditional diagnostic labeling of "Ode Ori" was the significance of "Ori" in Yoruba land which does not merely mean the head but the "destiny" ("ayanmo") which the individual brings into the world. ${ }^{11}$ It is believed by the Yorubas and Africans at large that things do not happen to an individual by chance but are usually predicated on the "ayanmo" the individual had 'chosen' before coming to the world.

\section{Ogun oru}

In a survey of 30 traditional healers in Yorubaland (in south west Nigeria) over 4 decades ago, "Ogun Oru" featured prominently describing a neuro-psychiatric condition with the following manifestations: the person is "attacked" at night while asleep, awakens and is unable to sleep again with agitation and exhibition of abnormal behaviour and may bleat like a goat. Furthermore, the illness is attributable to being poisoned by an enemy through eating in the dream. ${ }^{56}$ Scientific study of "Ogun Oru" was only recently undertaken by Aina and Famuyiwa ${ }^{63}$ The sample compried 3 patients seen over a 30 month period in the psychiatric unit of Lagos University Teaching Hospital (LUTH), Lagos, Nigeria with the "diagnosis" of "Ogun Oru" from traditional healers and a prophet. The possible differential diagnoses included parasomnias such as sleep terror, sleep walking and sleep paralysis, and to a lesser extent, nocturnal or sleep epilepsy 
(hypno-epilepsy). ${ }^{63}$

Literally, 'Ogun-oru' simply means 'nocturnal warfare' and it is traditionally believed to result from attacks of the victim by enemies operating at night. In Africa, the night is regarded as a sacred time when the evil ones (witches, evil spirits or demons and departed ancestors) go around wreaking havoc on people; the most vulnerable time is from

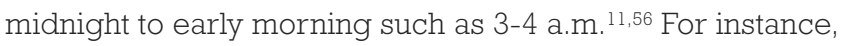
in a study of the concept of "Aje" (witches) among the Yoruba of south west Nigeria, it was generally found that "Ajes" are usually women possessed with the power or spirit of witchcraft to wreck evil most especially at night ${ }^{64,65}$ hence, the following Yoruba rendition on them:

"Iya mi osoronga

Olokiki oru

Aroso 'gba ma balẹ

Atifun jẹo

Ajedo joronro"

This is literally translated thus:

"My mother the witch

The controller of the night

The one that ties 200 wrappers with none of them touching the ground.

The one that consumes the liver from the intestine

The one that consumes both the liver and bile together"

The above clearly shows the perceived destructive power of the witches and their evil activities at night. Another important traditional explanation for "ogun-oru" is that it is a form of attack on the female victim by her "spiritual husband". In Africa, there is a popular belief that some female members of the society have husbands in the spiritual realm called "oko orun" or "oko omi" (spiritual or marine husband). The manifestations of such spiritual husbands include: the victim being barren in real life, as it is believed she must have gotten all her children in the spirit realm for her spiritual husband. Other manifestations are the recurrent experience of sex dreams by the victim and occasional absent mindedness when the victim is believed to commune with her spiritual husband. ${ }^{66}$ This belief is so strongly entrenched in the continent because Africans believe there are the material and immaterial worlds, the material world is inhabited by animate and inanimate beings, whereas the immaterial world is inhabited by the spirits, the gods and one almighty God; and beings from one world can cross over into the other world and vice versa. 67,68

\section{Culture bound concepts}

\section{"Abiku"/"Ogbanje"/ "Nitkubon"/ "Spiritual or marine} spouse"

Reincarnation is a popular belief in Africa ${ }^{69}$, and particularly in the southern part of Nigeria, "abiku" (among the Yoruba) and its equivalent "ogbanje" (among the Igbo) is a strong cultural concept. With this concept, the belief is that certain children die prematurely and could be born over and over again, usually by the same woman or in few cases by different women on different occasions. ${ }^{70,71}$

"Abiku" literally means born to die, while "ogbanjẹ" is interpreted as repeater or one who returns. The two concepts convey the same message, which is coming again; the human being repeatedly comes back to this life after death. It is also believed that the "abikus" or "ogbanjẹ" spend only few years before they die and in the process torment their parent through repeated cycles of short life spans. ${ }^{70,71}$ The cultural explanation for these concepts is as follows: "Abikus" are supposed to belong to a fraternity of demons living in the woods, especially about and within large "Iroko" trees; and each one of them coming into the world would have arranged before hand the precise time he would return to his demonic spiritual company. Where a woman has lost several children at infancy, especially after a short period of illness, the deaths are attributed to this cause, and means are adopted to thwart the plans of these infants in order that they may live; for if they can only tide over the pre-arranged date, they may not go back again to the demonic world, and thus entirely forget their spiritual company. Thus, parents in conjunction with traditional medicine men ("Babalawo" among the Yoruba and "Dibia" among the Igbo) would tie charms to "abiku" children or brand them with "ugly marks" to frighten away the spirit company and oblige the "abiku" to stay in their world.

Furthermore, some cultural names are given to make "abiku" children live longer. Examples of such names include "Kokumo" (do not die again), Malomo (do not depart again) and Kosoko (no more hoe to dig grave). ${ }^{72,73}$ The Igbo concept of "ogbanjẹ" is virtually identical to the "abiku" of the Yorubas. According to the Igbo anthropologists, the "ogbanje" die prematurely without any sign of ill health; but they can be stabilized to live by traditional medicine men ("Dibia"), provided they can be detected in time. ${ }^{73,74}$ Another cultural explanation for "o .gbanje" among the Igbos is that "ogbanje". is a group of adolescents who kept returning to earth after dying young and having other special propensities, such as living only 20 years and dying together thereafter, not to have children, not to marry, or to perform very specific task in returning again. ${ }^{73,75}$

"Abiku" and "ogbanje" have also been linked and/or culturally explained with affliction from water spirits popularly called "Mammy Water" or "water goddess" or "Queen of the Coast" or "Eze nwanyi" (in Igbo land) or "Yemoja" or "olokun" (in Yoruba land). It is believed that these water spirits are very powerful, troublesome, unfriendly and wicked. They are said to live under streams, rivers, seas and oceans. Water spirits are further believed to appear on few occasions as handsome men but usually as beautiful ladies to the extent that beautiful ladies in real life are usually nicknamed "mammy water" to show how they resemble the female water spirits. ${ }^{76}$ The cultural link between "ogbanje" and "abiku" is the belief that during transition, the water goddess who is pretty and very tempting will try to bring one away from his/her original life contract to fulfill her own. Those who get enticed by the water goddess will be under the influence of her group and herself. Thus, the individual would be living some years alternately between real life and spiritual one with the "mammy water" spirits (who on each occasion dictate the number of few years the individual lives in the real world). ${ }^{75,71}$ 
The mental health significance of "abiku" and "ogbanjẹ" phenomena include occasional reported cases of mass hysteria of water goddess looking for people to abduct. These cases of mass hysteria could be very challenging to the extent that in 1985 tragedy struck when some primary school pupils in Enugu, south eastern Nigeria allegedly saw a mermaid or water spirit coming to abduct them. The resultant stampede caused the death of about ten pupils in the school. ${ }^{75}$

Nowadays, it should be noted that in cities and towns of West Africa with relatively better child health care and infant survival rate "ogbanjẹ" and "abiku" phenomena are minimal. However, the concepts still persist in rural areas with poor orthodox healthcare and attendant high infant mortality rates. Finally, a very similar concept to "Abiku" and "ogbanje" has been described among the Wolof of Senegal, the so called "Nitkubon". It is a psychopathological syndrome among the Senegalese children that literally means "bad person". The affected child exhibits withdrawal, undue sensitivity, depression and temper tantrums. Other symptoms are crying episodes often terminated by akinetic spell.s. The parents are very fearful the child could die anytime; thus, the child is often understood to be either a visiting ancestral spirit or reincarnated ancestor who has ability to influence the time of its own death. ${ }^{78,79}$

\section{Pobough lang}

This CBS was first described among the Serer of Senegal by Beiser. ${ }^{80}$ The manifestations included earth (sand) eating, pallor, depression and social withdrawal with up to $0.5 \%$ of the Serer population being affected. ${ }^{80}$ It is believed that the disorder might fit the DSM criteria for pica. ${ }^{81}$

\section{Discussion}

For virtually all orthodox psychiatric practitioners in Africa, seeing one or more forms of the above described CBS in a therapeutic setting is a common occurrence. They pose management challenges not least of all because of the nonrecognition of most of them in the internationally accepted classification systems. 4, 13,15,18 This has not allowed the development of satisfactory treatment models with little or no research attention paid to them despite their prevalence on the continent. Thus, it is hoped that this review will stimulate a renewed interest in CBS in West Africa. There is no doubt that the poor response of patients to the presently known management strategies of these CBS poses a heavy burden on the fragile mental health care in West Africa. Thus, there is need for a paradigm shift in the nosological classification of mental illness so as to include these CBS in West Africa in the international classificatory system.

Such a call is not new. Anthropologists and some psychiatrists have criticized the older trans-cultural epidemiological research for imposing western concepts of psychopathology on non-western people. ${ }^{82-85}$ Furthermore, many scholars have criticized Europe and North America for their great influence on models and classification of mental illness without taking into consideration non-western cultures. ${ }^{86-88}$ For instance, ICD-108 has been criticized in cross cultural terms because out of 47 psychiatrists involved in drawing up the first draft, only two of them were from Africa. ${ }^{61,89}$ Thus, there are those who question why clinically significant and distressing symptom patterns seen as "bound" to non-Western cultures retain the status of syndrome (CBS) while other symptom patterns seen as clearly bound to Western culture are classified as "disorders". ${ }^{90,91}$ For instance, in a recent critique by Njenga, anorexia nervosa which is hardly known among Africans is classified as a disorder in the classification systems because it is a relatively common problem among girls in the western world. ${ }^{85}$ But despite their high prevalence in West Africa, virtually none of the CBS found in the sub-region described in this paper are included in the classificatory system.

\section{Conclusion}

It should be borne in mind that these culture-bound syndromes constitute great challenges for psychiatric practice in Africa. ${ }^{89,90,91,92}$ The current review suggests a need for a paradigm shift and a reassessment of the classification of mental illness, specifically with consideration being given to the inclusion of certain of these CBS - found in West Africa - in the International Classificatory System. .89

\section{References}

1. Hobbs DA, Blank SJ. Sociology and the human experience (eds). John Wiley \& Sons Inc. NY 1982.

2. Sadock BJ, Sodock VA. Anthropology and cross-cultural Psychiatry. Culture Bound Syndromes (eds.) In: Kaplan \& Sadock's Synopsis of Psychiatry. Behavioural Sciences/Clinical Psychiatry. Ninth Edition. Lippincott Williams \& Wilkins 2003: pp 166-170, $529-533$.

3. Lambo TA. Traditional African Cultures and Western Medicine: A Critical review. In FNL Poynter (Ed.) Medicine and Culture. London: Wellcome Institute, 1955: pp 201-210.

4. Binitie AO. The Clinical Manifestation of Depression in Africans. Psychopathologie Africaine 1982; 17: 36-40.

5. Morakinyo O. Phobic states presenting as somatic complaints syndromes in Nigeria: Socio cultural factors associated with diagnosis and Psychotherapy. Acta Psychiatrica Scandinavica 1985; 71: 356-365.

6. Prince RH. "The Brain-Fag Syndrome in Nigeria". Review and Newsletter, Transcultural Research in Mental Health Problem 1959; 6: 40-41.

7. Prince RH. The "Brain-Fag" syndrome in Nigerian Students. Journal of Mental Science 1960; 106: 559-570.

8. World Health Organization. International Classification of Diseases (10th ed). Geneva: WHO, 1992.

9. American Psychiatric Association. Diagnostic and Statistical Manual of Mental Disorders (4th ed). Washington DC: American Psychiatric Association, 1994

10. Cheng ATA. Case definition and culture: are people all the same? British Journal of Psychiatry 2001; 179: 1-3.

11. Kendler KS. Towards a Philosophical structure for Psychiatry. American Journal of Psychiatry 2005; 162, 3: 433-440.

12. Teuton J; Bentall R; Dowrick C. Conceptualizing Psychosis in Uganda: The Perspective of Indigenous and Religious Healers. Transcultural Psychiatry 2007; 44 (1): 79-114.

13. Ayonrinde K. "Heat in the head or body - A semantic confusion?". African Journal of Psychiatry 1977; 3: 59-63.

14. Logmo B. Cultural forms of Psychopathology. Paper presented at the Pan African Psychiatric Association Seminar, Yaounde, Cameroun, September, 1977.

15. Ebigbo PO; Ihezue UH. Uncertainty in the use of Western 
Diagnostic Categories for labeling mental illness in Nigeria. Psychopathologie Africaine 1982; 18: 353-362.

16. Majudina MZ; Attah-Johnson FY. Standardized assessment of depressive disorder (SADD) in Ghana. Transcult Psychiatric Res Rev. 1984; 21:201-202

17. Ayorinde S. "Okada" rider alleges theft of private part. The Punch (Ed). Punch (Nig.) Limited, Onipetesi Ikeja, Lagos. February 1, 2008: $p$ p5

18. Aina OF. Culture Bound Syndromes. A paper presented at the Faculty of Psychiatry, West African College of Physicians update course/workshop. Theme: "Transcultural Psychiatry", August 2007. Federal Neuropsychiatric hospital, Yaba, Lagos, Nigeria.

19. World Health Organisation, Working together for Health. World Health Report 2006. Geneva: WHO. http://www. who.int/whr/2006/annex/en. Accessed 7-1-2008.

20. Durowade O \& Taiwo O. Culture and society in Africa. In: Sophie B. Oluwole \& Kehinde Faluyi (Eds). The essentials of African studies vol.2. Lagos, Nigeria: General African studies Programme. pp $41-75$.

21. Byaruhanga-Akiiki ABT. Culture, spirituality and management. In David M. Ndetei (Ed). The African textbook of clinical psychiatry and Mental Health. The African Medical and Research Foundation, Nairobi, Kenya 2006: pg 119-22.

22. Jilek WG, Jilek-Aall L. The metamorphosis of "Culture-bound" syndromes. Social Science \& Medicine 1985; 21: 205-210.

23. Wintrob RM. The Cultural Diagnosis of student anxiety: A report from Liberia. Psychopathologie Africaine 1973; 9: 267-283.

24. Parin P. A case of "Brain-Fag" Syndrome: Psychotherapy of the patient Adou A. in the village of Yosso, Ivory Coast Republic. In (eds) W. Muensterberger, I. Bryce Boyer and S. A. Grolnick. The Psychoanalytic study of society, volume 10, New Jersey: Analytic Press; 1984: pp 1-52.

25. Minde KK. Study problems in Ugandan secondary School students; a controlled evaluation. British Journal of Psychiatry 1974; 125: 131-37.

26. Harris B. A case of Brain Fag in East Africa. British Journal of Psychiatry 1981; 138: 162-163.

27. Peltzer K, Cherian VI, Cherian L. Brain Fag symptoms in rural South African Secondary School pupils. Psychological Reports 1998; 83: 1187-1196.

28. Prince R. The Brain Fag syndrome. In: Karl Peltzer \& Peter O. Ebigbo (Eds). Clinical Psychology in Africa. A textbook for Universities and Paramedical schools. Chuka Printing Company Limited, Uwani - Enugu, Nigeria, 1989: pp 276-287.

29. Savage C, Prince R. Depression among the Yoruba in (Ed.) W. Muensterberger and S. Axelrad. The Psychoanalytic study of society 1967; 4: 83-98.

30. Thebaud E, Rigamer EF. Some considerations on student mental health in Liberia. African Journal of Psychiatry 1976; 1: 227-232.

31. Morakinyo O. A Psychophysiological theory of a Psychiatric illness (The Brain Fag syndrome) associated with study among Africans. Journal of Nervous and Mental Disease. 1980; 168: 84-89.

32. Morakinyo O. Personality variables in a Psychiatric illness associated with study among Africans. African Journal of Psychiatry 1980; 6: 1-5.

33. Morakinyo O. The Brain Fag Syndrome in Nigeria: Cognitive deficits in an illness associated with study. British Journal of Psychiatry 1985; 146: 209-210.

34. Ebigbo PO. Development of a culture specific (Nigeria) Screening scale of Somatic Complaints in detecting Psychiatric Disturbance. Culture, Medicine \& Psychiatry 1982; 6: 29-43.
35. Jegede RO. Psychiatric illness in African students: "Brain Fag" syndrome revisited. Canadian Journal of Psychiatry 1983; 28: 188-192.

36. Fatoye FO, Morakinyo O. Study difficulty and the "Brain Fag" Syndrome in South Western Nigeria. Journal of Psychology in Africa 2003; 13 (1): 70-80.

37. Edwards JW. Indigenous Koro, a genital retraction syndrome of insular south East Asia: A critical review. Culture, Medicine and Psychiatry 1984; 8 (1): 1-24.

38. American Psychiatric Association. Diagnostic and Statistical Manual of Mental Disorder: DSM-IV. Washington DC: American Psychiatric Press 1994.

39. Buckle C, Chuah YML, Fones CSL. A conceptual history of Koro. Transcultural Psychiatry 2007; 44 (1): 27-43.

40. Bartholomew RE. The social Psychology of 'epidemic' koro. International Journal of Social Psychiatry 1994; 40 (1): 46-60.

41. Jilek WG, Jilek-Aall L. Mass Hysteria with koro symptoms in Thailand. Archive Neurologie, Neurochirurgie und Psychiatric 1977, 142: 100-101

42. Tseng WS, Mo KM, Li LS, Chen GQ, Ou LW, Zheng HB. Koro epidemic in Guangdong, China. A questionnaire survey. The Journal of Nervous and Mental Disease 1992; 180(2): 117-123.

43. Tseng WS, Mo KM, Hsu J, Li LS, Ou LW, Chen GQ, et al. A sociocultural study of Koro epidemics in Guangdong, China. American Journal of Psychiatry 1988; 145: 1538-1543.

44. Kobler F. Description of an acute castration fear based on superstition. Psychoanalytic Review 1948; 35: 285-289.

45. Berrios GE, Morley SJ. Koro-like symptom in a non-Chinese subject. The British Journal of Psychiatry 1984; 145: 331-334.

46. Lapierre YD. Koro in a French Canadian. Canadian Psychiatric Association Journal 1972, 17: 333 - 334.

47. Chowdhurry AN, Bagchi DJ. Koro in heroin withdrawal. Journal of Psychoactive Drugs. 1993; 25: 257-258.

48. Anderson DN. Koro: The genital retraction symptom after stroke. British Journal of Psychiatry 1990; 157: 142-144.

49. Chand SP. Koro associated with phobia for AIDS. International Journal of Psychiatry in Medicine 1998; 28: 353 - 356.

50. Ifabumuyi OI, Rwegellera GGC. Koro in a Nigerian Male Patient: $A$ case report. African Journal of Psychiatry 1979; 5, iiii \& iv: 103-105.

51. Ogunlesi AO. Koro Symptomatology associated with paranoid Psychosis in a Nigerian Patient: A case report. West African Journal of Medicine 1986; 5; 4: 305-307.

52. Adeniran RA, Jones JR. Koro: Culture-bound disorder of universal symptoms. The British Journal of Psychiatry 1994; 164: 559-561.

53. Ilechukwu STC. Magical Penis Loss in Nigeria: Report of a Recent Epidemic of a Koro-like syndrome. Transcultural Psychiatric Research Review 1992; 29: 91-107.

54. Ilechukwu STC. Koro-like syndromes in Nigeria. Transcultural Psychiatric Research Review 1988; 25; 310-314.

55. Prince R. Indigenous Yoruba Psychiatry. In Kiev A (Ed). Magic, faith and healing. New York: Free press 1964: pp 84-120.

56. Simpson GE. Traditional Medicine: Diagnosis, causes and treatment of illness In (Ed). Yoruba Religion and medicine in Ibadan. Ibadan, Nigeria: Ibadan University Press: pp 93-113.

57. Makanjuola ROA. "Ode Ori". A cultural Bound disorder with prominent somatic features in Yoruba Nigerian Patients. Acta Psychiatrica Scandinavica 1987; 75: 231-236.

58. Wing JK, Cooper JE, Sartorius N. Measurement and Classification of Psychiatric Symptoms. Cambridge: Cambridge University Press, 1974.

59. American Psychiatric Association. Diagnostic and Statistical 
Manual of Mental Disorders. 3rd ed. Washington DC: American Psychiatric Association, 1980.

60. Odejide AO, Oyewunmi LK, Ohaeri JU. Psychiatry in Africa: An overview. American Journal of Psychiatry 1989; 146: 708-716.

61. Patel V. Explanatory models of mental illness in sub-Saharan Africa. Social Science \& Medicine 1995; 40: 1291-1298.

62. Morakinyo O. The Ayanmo Myth and Mental Health Care in West Africa. Journal of Cultures and Ideas, 1983; 1; 1: 61-92.

63. Aina OF, Famuyiwa OO. Ogun Oru: A traditional explanation for Nocturnal Neuropsychiatric Disturbances among the Yoruba of South West Nigeria. Transcultural Psychiatry 2007; 44 (1):44-54.

64. Prince R. The Yoruba image of the witch. Journal of Mental Science 1961; 107: 795 .

65. Verger PF. Iya mi Osoronga: My mother the witch. Paper presented at the Department of African Language and Literature Seminar, University of Ife (now Obafemi Awolowo University), IleIfe, Nigeria 1977

66. Aina OF. Mental Illness and Cultural Issues in West African Films: Implications for Orthodox Psychiatric Practice. Medical Humanities 2004; 30: 23-26

67. Nolan P. History of Psychiatry, Patients and Hospitals. Current Opinion in Psychiatry 2000; 13: 717-720.

68. Ebigbo PO. The mind, the body and society: An African Perspective. International Journal for the Advancement of Health 1987; 3 (4) : 45-57

69. Eneh ES. Reincarnation: Fact or Fancy? Enugu: Delta (Nigeria) Ltd. 1987.

70. Abraham RC. Dictionary of Modern Yoruba. London: University of London Press 1958.

71. Ebigbo PO, Ihezue UH. The "Ogba Nje" phenomenon and its significance for Psychotherapy in Nigeria. Zeit Schrift und Psychoanalyse. 1981; 27: 84 -91

72. Johnson S. The history of the Yorubas. Lagos. CMS (Nigeria) Bookshops 1921

73. Ilechukwu STC. Ogbanje/Abiku: A culture bound construct of Childhood and family psychopathology in West Africa. Transcultural Psychiatric Research Review 1990; 27: 197-200.

74. Uchendu VC. The Igbo of Southeast Nigeria. New Your: Holt, Rinehart and Winston 1965

75. Ebigbo PO, Anyaegbuna B. The problem of Student involvement in the mermaid cult $-A$ variety of belief in reincarnation (Ogba nje) in a Nigerian Secondary School. Journal of African Psychology 1988; 1: 1-14

76. Odinkemelu L. Mammy Water in the society (her influence in Igbo
Culture) Volume 1. A research on Mammy Water, the god of the sea. Ihiala, Anambra State: Sams Printing Press, 1987.

77. Achebe C. Ogba Nje. Enugu: Fourth Dimension 1986.

78. Zemple A, Robain J. ' 'L' enfant Nit Ku Bon, un Tableau Psychopathologique Traditional Chez Les Wolof et les Labou Du Senegal'. Psychopathologie Africaine 1965; I: 329-443.

79. Ortigues E, Ortigues MC, Zemple A, Zemple J. Clinical Psychology and Ethnology (Senegal). In K Peltzer, PO Ebigbo (Eds) Clinical Psychology in Africa, Enugu, Nigeria: Chuka Printing Company Limited: pp 7-18.

80. Beiser A. Pobough Lang in Senegal. Social Psychiatry 1974; 9: 123-129.

81. Osemwenkha SO. Olokun among the Edo. Case study of a culture bound syndrome. Nigerian Journal of Psychiatry 1997; 1; 4: 204-208

82. Kleinman A. Anthropology and Psychiatry: The role of Culture in Cross-Cultural research on illness. British Journal of Psychiatry 1987; 151: 447-454.

83. Kirmayer LJ. Culture, context and experience in Psychiatric diagnosis. Psychopathology 2005; 38: 192-196.

84. Wakefield JC. The concept of mental disorder: diagnostic Implications of the harmful dysfunction analysis. World Psychiatry 2007; 6: 149-156

85. Njenga F. The concept of Mental Disorder: an African Perspective World Psychiatry 2007; 6: 166-167.

86. Waxler NE. Culture and Mental Illness: a social labelling Perspective. J. Nerv Ment Dis 1974; 379-395.

87. Westermeyer J. Psychiatric diagnosis across cultural boundaries Am J Psychiatry 1985; 142: 789-805.

88. Neighbors HW, Jackson JS, Campbell L, et al. The influence of racial factors on psychiatric diagnosis: A review and suggestions for research. Community Ment. Health J 1989; 25: 301-311.

89. Puri BK, Hall AD. Cross-cultural Psychiatry. In (Eds.) Revision Note in Psychiatry. 2nd Edition. Oxford University Press. 2004 pp 519-528

90. Simons RC. Sorting the Culture-bound syndromes. In RC Simons \& CC Hughes (Eds.) Culture-Bound Syndromes: Folks Illnesses of Psychiatric and Anthropological Interest. Dordrecht, the Netherlands, D Reidel 1985: pp 25-38

91. Griffith EEH,González CA. Essentials of Cultural Psychiatry. In RE Hales; SC Yudofsky, JA Talbott (Eds.) Textbook of Psychiatry. 2nd Edition, American Psychiatric Press Inc. 2005: pp 1379-1404.

92. Haslam N. Dimensions of folk Psychiatry. Rev. Gen. Psychol 2005; 9: $35-47$



